\title{
Finitude, "Frequentação do Mundo" e Formação Humana em Michel de Montaigne
}

\author{
Rosana Silva de Moura' \\ 'Universidade Federal de Santa Catarina (UFSC), Florianópolis/SC - Brasil
}

\begin{abstract}
RESUMO - Finitude, "Frequentação do Mundo"1 e Formação Humana em Michel de Montaigne. $\mathrm{O}$ artigo propõe pensar a formação humana a partir de alguns aspectos da filosofia de Michel de Montaigne que nos são dados no texto clássico Ensaios. Inicialmente apresenta-se um desenho da época renascentista, chão de sua perspectiva antropológica, marcada pela importância do homem no mundo. Tendo por base uma hermenêutica dos ensaios montaigneanos, interpreta-se a ideia de finitude e de frequentação postas pelo autor enquanto elementos fundantes de seu horizonte filosófico. A contribuição da filosofia da educação de Michel de Montaigne aponta, justamente, para o caráter aberto e inconclusivo (e, por isso, rico) da vida, da formação humana e da educação.

Palavras-chave: Michel de Montaigne. Finitude. "Frequentação do Mundo”. Formação Humana. Filosofia da Educação.
\end{abstract}

ABSTRACT - Finiteness, "Frequenting the World" and Human Formation on Michel de Montaigne. The paper aims to think about the human development from some aspects of the philosophy of Michel de Montaigne offered to us in the classic text Essays. Initially, it introduces an outline of the Renaissance age, the basis of his anthropological perspective, marked by the man's importance in the world. Based on a hermeneutics of Montaigne's essays, it interprets the idea of finiteness and of frequentation brought by the author as part of foundational elements of his philosophical horizon. The contribution of Michel de Montaigne' philosophy of education points, precisely, to the open and inconclusive (and therefore rich) character of life, of human development and of education.

Keywords: Michel de Montaigne. Finiteness. "Frequenting the World". Human Development. Philosophy of Education.

Educação \& Realidade, Porto Alegre, v. 39, n. 4, p. 1169-1184, out./dez. 2014.1169 Disponível em: <http://www.ufrgs.br/edu_realidade> 


\section{Introdução}

Acompanhando a ideia e o movimento de uma perspectiva, há muitos modos de se abordar um horizonte filosófico. Minha opção para apresentar aspectos da filosofia humanista de Michel de Montaigne e com isso iniciar uma conversa sobre o tema tem a ver com minha historicidade, como penso que não poderia deixar de ser.

Oriunda da história e imersa na filosofia (especialmente da educação), sou chamada a fincar a filosofia no chão do tempo, situando o modo de pensar do filósofo. Daí a iniciativa do reconhecimento do peso do espírito do tempo (Zeitgeist) para uma incursão filosófica, pois nosso filósofo é, como se diz comumente, "um homem de seu tempo". O espírito da época fala no autor e na obra. Nesse sentido, gostaria de destacar elementos do seu tempo que o constituem subjetivamente, aparecendo em seu horizonte filosófico mesmo quando seu pensamento cambaleia (Montaigne, 2002).

Com esses elementos desenha-se uma constelação na qual podemos visualizar no presente o que este clássico ainda nos diz sobre o humano, seguindo talvez a única certeza que ele nos indica, a saber, “[...] o homem é um assunto espantosamente vão, variado e inconstante. Sobre ele é difícil estabelecer uma apreciação firme e forte" (Montaigne, 2002, p. 10-11). Tão vasto pensamento nos obriga a manifestar, de saída, o limite do recorte feito aqui.

Sob esta orientação podemos pensar possíveis movimentos no horizonte da filosofia da educação como um lugar que pode nos levar a pensar questões como educação, formação, autoformação, no impasse que a educação escolar nos põe no contemporâneo. Nesse sentido, quando me refiro à filosofia da educação tenho presente críticas de Adorno (1995) e Flickinger (1998) sobre o paradoxo contido na forma disciplinar que o currículo impõe à filosofia da educação. Todavia, tendo em vista certa carência de reflexão no universo escolar, muitas vezes me pergunto: Como fazer a filosofia da educação acontecer de outra forma nos tempos atuais? O paradoxo nos impõe o impasse que nos convoca ao risco.

A Montaigne, então.

\section{O Zeitgeist Renascentista: o chão da filosofia de Montaigne}

Montaigne nasce Michel Eyquem de Montaigne, em 1533, em Saint-Michel de Montaigne, no sudoeste da França, na Aquitânia, região historicamente disputada, conforme atestam historiadores (Rouche, 1989; Bloch, 1982) e lá morre com 59 anos (1592), também em Saint-Michel de Montaigne (Chauí, 1987; Miller, 2012). Como podemos imaginar, um território longamente disputado belicamente e fragmentado deve impregnar nos espíritos do lugar um sentimento de finitude e anseios de conversação: um “[...] anseio por uma vida mais bela [...]” (Huizinga, 
2010, p. 47-48). Apesar de lá nascer e morrer, durante sua vida viajou não só por seu país, como também pelo continente europeu: por certo o destaque que dá às viagens como elemento formativo do humano venha de suas próprias vivências como viajante por entre modos diferenciados das culturas e seus costumes. Uma disposição de espírito que marca, sobremaneira, a filosofia do viajante.

Curiosamente, quando lemos os Ensaios percebemos certo movimento contínuo nos deslocando entre um tema e outro, de modo inconcluso, como se houvesse uma intenção de não fechar porta alguma, nada que seja peremptório ou que nos lance a ideia de uma certeza acabada, pronta e da qual nada mais se pode dizer, mas, sim, de uma entreabertura na qual ainda se vê alguma possibilidade. Pois, como ele mesmo diz, "Da frequentação do mundo tira-se uma admirável clareza para o julgamento dos homens. Estamos todos trancados e encolhidos em nós mesmos e temos uma visão limitada ao comprimento do nosso nariz" (Montaigne, 2002, p. 235).

É desta belíssima e lúcida imagem da frequentação do mundo, como uma atitude de liberdade humana que ele projeta também sua antropologia, pois, como refere, "Este grande mundo, que alguns multiplicam como espécies sob um gênero, é o espelho em que devemos olhar para nos conhecermos da perspectiva certa" (Montaigne, 2002, p. 236). Sem sombra de dúvidas, o mundo é um espelho formativo para este filósofo. Daí, em certa medida, sua ascendência sobre a construção da identidade da antropologia como um campo de conhecimento, no qual o ensaio Dos Canibais ainda repercute. Vemos aí que, para Montaigne, assim como para todo o movimento renascentista, a relação com o mundo, o homem e o corpo é fundamental para a realização da obra. Entra em questão uma larga discussão filosófica sobre cultura e natureza, da qual não lanço mão no momento. Mas cabe dizer que por isso, talvez, por esta disposição de estar no mundo, o filósofo não tenha se furtado a exercer cargo público, o que se torna possível em função de sua formação em Direito, na Universidade de Toulouse. E é justamente pela porta da universidade que os convido a adentrar no chão de sua filosofia.

A Universidade de Toulouse, fundada em 1229, compõe o conjunto das instituições de ensino que contribuíram para as mudanças na Europa (lembrando que Marrocos e Egito já as tinham desde o século $\mathrm{X}$ ), acentuando o fim da Idade Média (XI-XV), difundindo e fortalecendo o novo Zeitgeist embebido no que conhecemos como humanismo. Na verdade, trata-se de um projeto que repousa na disposição de trazer à luz o texto a obra do clássico antigo, como de resto foi orientação primeira espraiada por todo o Renascimento. Por isso, nesse tempo e cenário, torna-se importante dizer que, primeiramente, temos a expansão no Ocidente das universidades, criadas no século XII, com especial destaque para o trabalho que ali se desenvolvia com a tradução dos textos

Educação \& Realidade, Porto Alegre, v. 39, n. 4, p. 1169-1184, out./dez. 2014.1171 Disponível em: <http://www.ufrgs.br/edu_realidade> 
clássicos, o que acentuava uma preocupação com a linguagem, algo de que se ocupa também nosso filósofo.

Então, o surgimento e expansão das universidades foi, por certo, a mola propulsora do espírito do tempo renascentista, digamos, o lugar mor da fabricação daquele espírito. Sobre a convergência da questão do surgimento das universidades e os intelectuais na Idade Média, Jacques Le Goff, quando fala de uma "[...] modernidade do século XII [...]" (Le Goff, 2003, p. 34) e seus homens, os intelectuais, lembra-nos que aqueles tempos se ergueram a partir da necessidade de "Fazer o novo [...]" e de os homens "[...] serem homens novos - disso os intelectuais do século XII tiveram vivo sentimento. E haverá renascimento se não houver impressão de renascer?” (Le Goff, 2003, p. 34).

Universidades, espírito inquieto fortemente inclinado a se ocupar de investigações dos fenômenos naturais, inventivo no que diz respeito aos experimentos com a ciência, aberto às artes tanto para a criação quanto para fruição e mecenato, o Zeitgeist renascentista continha elementos para produzir nos homens uma vontade de experimentar a vida na sua complexidade. O humanismo renascentista iniciado na Itália e expandido pela Europa, como sabemos, tem como orientação fundamental se ocupar das questões do homem no sentido universal, mas com vistas à sua inserção no mundo por meio do corpo. Uma tentativa de contrabalancear a pesada teologia medieval onde corpo e mundo haviam sido silenciados. Trata-se de um momento no qual o homem tem como projeto principal recuperar seu lugar no mundo por meio de um antropocentrismo sufocado durante o teocentrismo medieval. Logo, homem, mundo e corpo são os elementos que constituem a base de toda a investigação da Renascença. Efetivamente naquele Zeitgeist é retomada a enunciação do sofista Protágoras, de que o homem é a medida de todas as coisas.

De modo mais delimitado e concreto ainda encontramos o corpo do homem, como quis nos mostrar Leonardo da $\mathrm{Vinci}^{2}$, ele próprio um exemplar da excelência do humano, reunindo numa personalidade Ars et sciencia ${ }^{3}$. Nesse momento, o humanismo renascentista se apresenta ao mundo como um modo de traduzir homem e mundo a partir de uma perspectiva encarnada, falando sempre a partir do corpo, herança do aristotelismo, invertendo a metafísica platônica (veja-se, por ex., a emblemática e conhecida obra de Rafael, A Escola de Atenas). Encontramos aí elementos históricos que compõem o desenho do Zeitgeist, conferindo uma marca antropológica na filosofia montaigneana. No entanto, e para não desmerecer a legitimidade de sua antropologia e seu ceticismo em relação às certezas absolutas da razão, ele se pergunta constantemente sobre o que realmente sabe (e sabemos), se colocando criticamente frente à erudição que soasse como um arremedo de cultura, enunciando que não deveríamos nos comportar como "[...] burros carregados de livros" (Montaigne, 2002, p. 265) ${ }^{4}$.

1172 Educação \& Realidade, Porto Alegre, v. 39, n. 4, p. 1169-1184, out./dez. 2014 Disponível em: <http://www.ufrgs.br/edu_realidade> 
Para ele, importa a vivência que oferece as condições da experiência formativa. No conhecido ensaio XXVI, Montaigne reporta à natureza enquanto espelho para a formação humana dizendo, "As abelhas sugam das flores aqui e ali, mas depois fazem o mel, que é todo delas [...]", para nos chamar a atenção do caminho próprio e singular que precisa ser a experiência formativa (Montaigne, 2002, p. 227). Sua ideia é a de que vida e arte estejam irmanadas e contempladas em uma possibilidade de filosofia de vida, na qual a experimentação é fundamental para a formação humana, "Pois que a filosofia é a que nos ensina a viver e a infância tem nela sua lição, como as outras idades, por que não lha transmitimos?" (Montaigne, 2002, p. 243).

Dizendo isto ele não pretende desmerecer a tradição, ao contrário, vale-se dela para compor a riqueza de sua autoformação humanista resguardando o valor do seu lugar de intérprete e de seus conteúdos quando diz:

Não travei relações com nenhum livro sólido, exceto Plutarco e Sêneca, em quem me abasteço como as danaides, enchendo e vertendo sem cessar. Fixo alguma coisa disso neste papel; em mim, praticamente nada. A história é mais minha seara; ou a poesia, que amo com uma inclinação especial (Montaigne, 2002, p. 218).

Tais palavras poderiam confundir o leitor mais apressado. Contudo, em toda sua obra espraia-se um diálogo com a tradição. O que Montaigne pretende é afastar-se de um uso instrumental da tradição, ao modo de uma erudição vazia e enfadonha. Nesse aspecto, suas palavras convergem para o sentido da vida quando enuncia: "O verdadeiro espelho de nossos discursos é o curso de nossas vidas” (Montaigne, 2002, p. 251).

Como sabemos, é marcante na cultura renascentista e presente sobremaneira na obra de Montaigne o recurso do uso das fontes greco-latinas como modo de manutenção de uma finalidade (télos), a saber, o formativo espiritual. Nesse sentido, Montaigne não traz o inusitado, ao contrário, o recurso era mesmo usual naqueles tempos renascidos, revitalizados na expressão e ação humanas. Ou seja, o uso do clássico como modo de atualizar a formação espiritual, considerando-se a força vigorosa que todo clássico contém justamente porque fala através de uma linguagem universal, comum no sentido que atinge a humanidade dos homens. Esta característica faz do clássico mais do que erudição, tornando-o texto aberto a todos os homens.

Por isso, também, se pudéssemos (e quiséssemos) eleger o mais crítico de todos os filósofos, mesmo assim veríamos que ele não se furta ao uso da tradição como modo de falar do humano e dos elementos que se atualizam de geração em geração, constituindo o terreno do mundo da vida e do qual extrai seiva e conteúdos (em horizonte mais específico da filosofia, tais conteúdos são tomados como elementos ontológicos,

Educação \& Realidade, Porto Alegre, v. 39, n. 4, p. 1169-1184, out./dez. 2014.1173 Disponível em: <http://www.ufrgs.br/edu_realidade> 
ou seja, coisas que estão em todos os humanos independente dos lugares que ocupam no mundo).

No entanto, acompanhando a exaustão do tempo, também nos deparamos com a face sombria da Renascença pelo ceticismo em relação aos alcances da razão e da ciência e da capacidade do homem de conhecer. Sob esta orientação, Michel de Montaigne nos oferece duas qualidades que deveriam constituir as subjetividades dos filósofos, marcando suas filosofias, que é a humildade e a generosidade. Montaigne duvida, cambaleia, como ele diz, tem medos e inseguranças, não vê com precisão uma forma definitiva para aquilo do qual se refere, e este modo de colocar o problema tem como base um ceticismo que o orienta, lançando a ideia da finitude das coisas.

Homem de seu tempo, porque reflete esta perspectiva e herança, e transcendente a ele, porque leva a sério a angústia de ser livre, Montaigne semeou questões no solo da filosofia tal como Nietzsche inventou problemas que arejaram a tradição do pensamento ocidental. Podemos dizer, inclusive, que muitos dos problemas levantados por Montaigne foram retomados, numa performance mais trágica é certo, por Nietzsche, que rasgava o pano das verdades de modo mais incisivo. Mas Montaigne ainda era um fidalgo; sua extemporaneidade flui descontínua. Como de resto não poderia deixar de ser, sua historicidade o denunciava, mas também o torna um clássico tratando de questões humanas que não se restringem à especificidade do tempo histórico. Ele assume o limite da compreensão, o limite da razão.

\section{O Estilo Ensaístico como Forma que Desvela Algo do Conteúdo Filosófico}

“A cada minuto me parece que escapo de mim [...]", nos confidencia Montaigne (2002, p. 129). O que nos sugerem estas palavras? Por certo, a ideia de que o estilo da escrita de Montaigne nasce da incerteza dos julgamentos (como ele mesmo intitula um ensaio homônimo). O autor não retém, não fixa por muito tempo um juízo. Sabedor de possuir uma "razão tênue" ${ }^{5}$ o filósofo não se arrisca em proferir sentenças que contenham certezas absolutas, eternas e resolutivas.

\footnotetext{
Digo mais, que mesmo nossa sagacidade e reflexão seguem quase sempre o comando do acaso. Minha vontade e meu raciocínio movem-se ora de um modo ora de outro e há muitos desses movimentos que se governam sem mim. Minha razão tem impulsos e agitações diárias e acidentais (Montaigne, 2001, p. 223).
}

Seu objeto é o humano e como tal constituído de matéria orgânica, transitória, circunstanciada. Sua escrita acompanha o fluxo não sistemático do pensamento que se abre na perspectiva estética, mais que epistemológica (Adorno, 1994). Por isso, seus escritos não pretendem

1174 Educação \& Realidade, Porto Alegre, v. 39, n. 4, p. 1169-1184, out./dez. 2014 Disponível em: <http://www.ufrgs.br/edu_realidade> 
argumentar através de uma linearidade. Nesta filosofia ensaística, conteúdo e forma se identificam na tentativa de dizer o possível no instante.

Como pensa Montaigne para apontar a forma ensaística como modo de dizer seu pensamento?

\begin{abstract}
Quanto às faculdades naturais que existem em mim, cujo ensaio aqui está, sinto-as vergar sob a carga. Minhas concepções e meu julgamento só avançam às apalpadelas, cambaleando, tropeçando em falso: e, mesmo quando vou o mais longe que posso, ainda assim não fico nem um pouco satisfeito: ainda vejo um território além, mas numa visão turva e nublada, que não consigo decifrar. E quando me proponho falar indiferentemente de tudo o que se apresenta à minha fantasia e empregando nisso apenas meus meios próprios e naturais, se me advém, como ocorre amiúde, de encontrar por acaso nos bons autores esses mesmos assuntos que decidi abordar (Montaigne, 2002, p. 218-219).
\end{abstract}

Correntemente, diz-se que o gênero ensaio tem uma brevidade e um não compromisso com o método científico, com a ciência, razão pela qual podemos pensar dele como sendo algo distanciado de um tratado e bem mais próximo de um texto livre que transita entre territórios e conteúdos como o da arte (compreendida aqui como letras), da ciência e mundo da vida. Daí também seu vínculo forte com elementos estéticos. O ensaio fala de um tema, procurando ampliar a dimensão de racionalidade nele presente, incorporando elementos afetivos e volitivos dados não só como tema, mas também no modo como seu autor se coloca na abordagem dos mesmos.

No ensaio, o autor se permite o jogo dialético e expressivo entre subjetividade e objetividade no tratamento do tema proposto. Isto aparece claramente no texto montaigneano onde acompanhamos amiúde o autor se expondo em primeira pessoa (ele, inclusive, não foge do uso do pronome eu). Especificamente no universo da palavra escrita, o ensaio é uma forma de dizer algo que seja o mais abertamente possível, entendendo assim a complexidade da coisa a se dizer e da impossibilidade dela tudo dizer. $\mathrm{O}$ fato de dizer algo de modo breve e parecendo incompleto não significa, nesta proposta, um desleixo para com a verdade da coisa; é justamente o contrário: a complexidade da coisa é que a torna inapreensível no todo no momento da escrita. Sempre encontramos algo de intangível no tema, de intraduzível, quando o tratamos de modo honesto. Assim, no ensaio mistério e aparição entram em acordo para compor a coisa em questão. Assim sendo, o movimento em cena de ambos, mistério e aparição, irá compor o conhecimento possível da coisa que nos é dado somente em perspectivas. Ou seja, o ensaio tem uma forma de abertura que desvela a natureza do próprio conteúdo, pois não seria ele mesmo a tradução de uma espécie de flânerie, um voo pelo tema?

Educação \& Realidade, Porto Alegre, v. 39, n. 4, p. 1169-1184, out./dez. 2014.1175 Disponível em: <http://www.ufrgs.br/edu_realidade> 
Assim, especialmente no horizonte da filosofia, a forma ensaística é um esforço para dizer o ente e sua complexa situação no mundo. Tarefa difícil, porque aí encontramos o elemento de intraduzibilidade que toda situação hermenêutica contém. Afinal, não somos oniscientes tampouco onipresentes. Por isso, o ensaio é uma tentativa de interpretação que transita entre o querer dizer e o não poder fazê-lo de modo inteiro, completo. Como diz Adorno (1994, p. 168), “[...] o ensaio evoca liberdade de espírito [...]”, a qual não estamos familiarizados por conta dos aprisionamentos cotidianos (e acadêmicos, por que não?) seja na esfera da ignorância que nos engessa pela carência do que dizer seja na esfera do cientificismo nos retendo em uma pseudoautonomia.

Nesse sentido, ainda seguindo Adorno,

\begin{abstract}
O modo de o ensaio se apropriar dos conceitos seria, antes, comparável ao comportamento de uma pessoa que, encontrando-se num país estrangeiro, vê-se obrigada a falar a língua deste, ao invés de compô-la escolarmente a partir de certos elementos. Essa pessoa, digamos, vai ler sem dicionário. Quando tiver visto trinta vezes a mesma palavra em contextos sempre cambiantes, então ela estará mais segura quanto ao seu sentido do que se tivesse olhado no dicionário a lista de significados, que, na maioria dos casos, são demasiados estreitos em comparação com os matizes de acordo com o contexto, e demasiado vagos em comparação com os inconfundíveis nuances que esse contexto oferece em cada caso individual. E assim como esse modo de aprender permanece sujeito a erro, o mesmo se dá no ensaio como forma; por sua afinidade com a experiência espiritual aberta, ele tem de pagar com aquela falta de segurança que a norma do pensamento institucionalizado teme como se fosse a morte (Adorno, 1994, p. 177).
\end{abstract}

Sob este prisma, conteúdo e forma resguardariam um espaço para o espanto, para a curiosidade e para o se deixar levar pelo tema como verdadeira experiência estética imanente do ato da escrita e do pensamento: vida, filosofia e formação, assim, resguardariam, tal como a forma ensaística, certa “disponibilidade infantil” (Adorno, 1994, p. 168) para aprender conteúdos da vida. Surpresa, espanto, curiosidade, jogo, se destacam aí como características imanentes do pensar filosófico quando enraizado nos conteúdos da vida. E esta é uma posição cara à filosofia contemporânea.

No caso de Montaigne, a forma ensaística quer traduzir o sentimento de algo que lhe escapa, impresso em sua subjetividade. Pois, ele sabe que o mundo, a vida e o homem não têm uma inteireza; não são formas completas que nos oferecem conteúdos permanentemente lógicos cuja origem e finalidade podem ser facilmente apreendidos. Não. Montaigne sabe que uma forma sistemática e retilínea é um artifício que quase nunca corresponde ao conteúdo caótico, desordenado, não linear e desorganizado da vida. A dinâmica da vida não é regida por leis

1176 Educação \& Realidade, Porto Alegre, v. 39, n. 4, p. 1169-1184, out./dez. 2014 Disponível em: <http://www.ufrgs.br/edu_realidade> 
inexoráveis. De modo honesto, Montaigne segue o ritmo da complexidade sobre a qual fala: sua escrita pretende refletir a vida encarnada do pensamento e inspira uma filosofia da vida. Ele se detém na dúvida, na incerteza, interroga.

Entretanto, para uma cabeça acostumada às respostas, o ensaio pode ser visto como um problema grave considerando o caráter relativista e não diretivo que a verdadeira pergunta nos coloca e que tem a ver com o desconhecido. Assim, o estilo ensaístico é uma forma de dizer algo que desvela um conteúdo filosófico e sua condição finita. Ensaio e finitude fazem o único casamento perfeito de que se tem notícia e quanto mais incompleta é a coisa que se diz, mais aberta ela é. Quanto mais se diz, mais se trai, e isto é a medida da própria condição que encerra a tentativa de tradução de algo. Nesse sentido, temos aqui uma contribuição forte da filosofia de Montaigne para nossa interpretação contemporânea do tempo.

\section{A Característica Antropológica de Sua Filosofia}

Amiúde, ao longo dos Ensaios, Montaigne estará se referindo à percepção que tem do mundo e que lhe é dada através de canais corpóreos e de sentimentos que compõem a vida humana. Uma filosofia traduzindo-se esteticamente porque sensível. Sob este aspecto, Montaigne se encontra no horizonte de uma tradição vinculada à tradução de mundo já posta em Aristóteles, basicamente porque ancora toda a percepção e interpretação desde um lugar, um spatium ${ }^{6}$, como diz Aristóteles na Física, habitado corporalmente no mundo. Assim, Montaigne está nos dizendo de sua marca antropológica, comumente relacionada ao ensaio. Todavia, esta perspectiva antropológica se encontra esparramada ao longo dos três volumes dos Ensaios: essa marca é facilmente visualizada nos temas elencados como tristeza, constância e moderação, medo (e da covardia), solidão. Isto tem a ver com a proposta enunciada por ele que pode ser encontrada, por exemplo, nos escritos sobre a educação da criança, de 1579-1580, nos quais se explicita uma filosofia em primeira pessoa, evidente traço do lugar subjetivo de onde o autor fala.

Ele também fala de temas supostamente banais, no sentido de serem aqueles que constituem nossos dias, tais como os "da ociosidade", "do dormir", "da arte da conversação", "do hábito de vestir-se", "das sutilezas vãs", "dos cheiros". E para compreendermos seu viés fortemente antropológico ele nos oferece o ensaio no qual se dedica a falar sobre a experiência que, como sabemos, é o traço fundante de toda a sua antropologia filosófica. Conforme atesta: "Enfim, toda essa miscelânea que vou garatujando aqui não é mais que um registro dos ensaios [experiências] de minha vida, que, para a saúde interior, é bastante exemplar desde que se tome a contrapelo a instrução [...]" (Montaigne, 2001, p. 444).

O curso da vida é o verdadeiro discurso que dela temos. Então, a experiência, para Montaigne, é aquela que conhecemos como experiência

Educação \& Realidade, Porto Alegre, v. 39, n. 4, p. 1169-1184, out./dez. 2014. 1177 Disponível em: <http://www.ufrgs.br/edu_realidade> 
de vida, daí a importância da frequentação do mundo à qual ele refere. Dela extraímos os elementos para dizer de um caminho próprio, como já referido antes. Aí podemos acrescentar: sua educação como um lugar próprio e intransferível; uma autoformação, uma experiência estética dada no trânsito pelo mundo (e, me parece, de modo algum, solipsista). E esta frequentação do mundo - e dos homens, cabe dizer, não se dá apenas no trânsito intercultural, mas relacional, o que se nota no texto mais explicitamente dado à filosofia da educação, o "Da educação das crianças", quando ele nos adverte sobre a importância de a criança, desde cedo, transitar pelas diferenças do mundo (a despeito de seu próprio distanciamento do mundo, a certa altura de sua vida, conforme atesta sua biografia - em 1567, com 34 anos permanece por algum tempo recluso) $)^{7}$.

Nessa perspectiva, penso que a subjetividade exposta em Montaigne, repercutindo na linguagem desde a figura de um eu, tem na frequentação do mundo um ponto de encontro que nos levaria ao prenúncio de uma intersubjetividade que se desdobrou mais tarde como efeito da modernidade. A filosofia de Montaigne vem toda do homem no mundo; vem toda do corpo. É uma filosofia encarnada, nada metafísica. A visão que este pensador tem do mundo não é de um lugar inteiro, resoluto e prontamente dado a nós. Ele vê o mundo e o traduz desde os particulares e mesmo quando alinhava um tecido mais extenso o faz tendo em vista algum elemento que capturou do cotidiano, do modo de vida dos homens que observou. Montaigne se encontra orientado pelo sentido da vivência, assim como aqueles que se preocuparam em compor uma filosofia da vida (como mais tarde, no século XIX, Dilthey e Nietzsche farão a defesa) ${ }^{8}$.

É por meio de uma frequentação do mundo que nosso filósofo encontra os conteúdos do mundo da vida dos quais ele lança mão para compor o alimento de seu espírito, daí o belo recurso de linguagem utilizado na metáfora dos temperos, tomilho e manjerona: misturados, enriquecem a vida, dando-lhe sabor. Temos aqui a formação espiritual de Montaigne, visivelmente traduzida em autoformação. Como referi antes, o mundo torna-se espelho formador quando nos dispomos a frequentá-lo efetivamente, vale dizer, esteticamente, experimentando- o com o corpo. Essa característica viajante desvela o ritmo do pensamento montaigneano: a linguagem do filósofo obedece ao ritmo fugidio e incompleto de seu pensamento e que aparece no momento do relato. Trata-se de uma escrita marcada por aquilo que, na hermenêutica, chamamos de situação, na qual o lugar de onde se fala marca sobremaneira o que se diz e não se tem a intenção de ocultamento desse lugar.

A peculiaridade de sua filosofia desponta no modo como ele diz a coisa, sabendo que o relato de toda experiência é em si uma visão de mundo circunscrita a um lugar, uma posição que nos dá uma perspectiva e não outra. Por isso, sua forma de abordagem de determinado tema

1178 Educação \& Realidade, Porto Alegre, v. 39, n. 4, p. 1169-1184, out./dez. 2014 Disponível em: <http://www.ufrgs.br/edu_realidade> 
só pode se manter nos limites do ensaio - ele sabe que não poderia dizer tudo sobre aquilo que diz no momento. Não possui a pretensão resolutiva e conclusiva do dizer. Nada parecido com o que dirá mais tarde Bacon $^{9}$ (1561-1626) sobre seguir astutamente a natureza para melhor dominá-la, tampouco semelhante a Descartes ${ }^{10}(1596-1650)$ e seu método querendo dizer tudo, do mais simples ao mais complexo. Montaigne não possui método e nem é explicativo. Suas perguntas sobre a condição humana são tão abertas quanto desconhecidas suas respostas. Suas dúvidas são verdadeiras, pois realmente abrem mundos, pois seus conteúdos têm menos intencionalidade retórica do que gostariam os primeiros modernos que acreditam no poder explicativo da razão. Nesse sentido, a abertura que a pergunta nos deixa tem mais a ver com a virada paradigmática da segunda metade do século XX que com os momentos que encetam as primeiras questões para a modernidade, como é o caso do Renascimento. Assim sendo, a antropologia de Montaigne encontra-se situada: ele nos fala do universal, da humanidade, a partir de si mesmo: ele se dedica a extravasar seu particular como um modo de dizer o que há de comum entre os homens.

\section{A Morte e a Filosofia: a questão da finitude como legado maior para a filosofia}

Como não poderia deixar de ser, uma filosofia que trata de modo tão antropológico suas questões, precisa, em algum momento, debruçar-se sobre aquilo que lhe constitui desde sempre, que é o tensionamento entre vida e morte, pois o que está vivo caminha, inexoravelmente, para seu fim; o que está vivo, o que é bios ${ }^{11}$, contém sua própria decomposição. Ou seja, seu elemento transitório, finito. A identidade da vida se dá no oposto, a morte, que lhe complementa o sentido e somente a partir daí, sua totalidade. Negar a morte como elemento intrínseco do que é vivo é negar a própria substância da vida.

Contudo, Montaigne não tem a intenção de tecer um elogio à morte, mas, antes, defender e ressaltar a vida por meio de uma filosofia que fale dela de modo mais verdadeiramente possível: que a morte sirva para nos mostrar quão a vida urge pelo instante, no presente e não para além dele. Nesse sentido, as filosofias que pretendem ser representadas por grandes sistemas, de modo contumaz, perseguem a ideia da permanência das coisas menosprezando a finitude e o limite delas. Menosprezar a finitude das coisas se torna um modo de a razão poder lançar certezas indubitáveis. Um modo de confeccionar seguranças em que o solo é movediço.

Em contrapartida, a ideia plantada pelo filósofo encontra ressonância perfeita na forma ensaística de como ele traduz a filosofia no seu instante de captura das coisas do mundo, do humano. Neste aspecto, e para ilustrar, encontramos o legado da filosofia de Montaigne em Nietzsche que afirmou, em texto de 1873 , serem as “[...] verdades um

Educação \& Realidade, Porto Alegre, v. 39, n. 4, p. 1169-1184, out./dez. 2014.1179 Disponível em: <http://www.ufrgs.br/edu_realidade> 
batalhão móvel de metáforas [...]" (Nietzsche, 1983, p. 48) e apenas uma invenção humana. No entanto, como é percebido contemporaneamente, a impermanência, finitude e limite das coisas estão aí e esbarramos nelas cotidianamente. E Montaigne já as tinha presente.

À luz dos textos clássicos elencados por ele (Cícero, Horácio, Catulo, Lucrécio, entre outros) e dos quais lança mão para dizer do humano no conjunto de seus ensaios, Montaigne vai desenhando sua própria ideia da finitude da vida e da imperiosa necessidade de vivê-la agora, justamente porque não é eterna. No ensaio sugestivamente intitulado Que filosofar é aprender a morrer, ele nos diz que "Desde sempre, não há algo que me tenha ocupado mais do que os pensamentos sobre a morte: mesmo no período mais desregrado de minha vida [...]" (Montaigne, 2002, p. 129). Orientado pela intuição de que o reconhecimento da presença da morte na vida nos ensina a viver, porque nos ensina a vê-la como algo finito, não admitindo protelamentos, a vida nos chama à liberdade de dizer-lhe sim. A partir desta compreensão o filósofo francês, inspirado incialmente em Cícero, enuncia que "Quem aprendeu a morrer desaprendeu de servir" (Montaigne, 2002, p. 128), como um modo primeiro de viver, em liberdade. Então, como um elogioso Carpe Diem ${ }^{12}$.

A primeira questão que me vem à mente sobre esta assertiva é a de que somente de uma perspectiva antropológica ele poderia tecer esta enunciação porque a morte é a outra face da vida e isto tem uma impregnância tão evidente em nossa apreensão da vida que quase nem percebemos sua presença. Interpretando a obra de Pedro Almodóvar, podemos pensar que a morte é uma "pele que nos habita"13, que nos faz trágicos na arte e na vida e desde sempre. Algo que quase tornamos invisível e, prova disso, é que poucas vezes nos damos conta das suas múltiplas formas. Quantas vezes percebemos as pequenas e impalpáveis mortes simbólicas que adensam os nossos dias? De quantos lutos somos feitos, ainda vivos? Assim, a vida aparece mais como um movimento no qual nossos dias passam e neles as pequenas partículas de toda espécie de coisa e vida que compõem nossos corpos e modos de estar no mundo vão se extinguindo, deixando de ter uma forma, morrendo ali para fazer-se outra. Muitas vezes, nos aferramos às formas existentes e resistimos às outras, dos devires. Nestes momentos a transformação tem a cara da morte mais primária, rudimentar, aquela do fim como uma perda. Advém-nos o luto. Aceitar a morte seria aceitar o limite da razão, do eu, do controle. Afinal, "[...] quantas formas de surpresa tem a morte?” (Montaigne, 2002, p. 125). Mesmo não sendo surpresa que morreremos, quando ela nos encontra, nos surpreende, então, quanto dessa surpresa suportamos? Quanto de sobressalto e desconforto suportamos no caminho que chamamos vida? "É incerto onde a morte nos espera; esperemo-la em toda a parte” (Montaigne, 2002, p. 128).

Quem quer, no seu eu ideal, supostamente imortal, não ser? Quem ousa e suporta escapar de si? (E por quanto tempo?). Esse escape, como

1180 Educação \& Realidade, Porto Alegre, v. 39, n. 4, p. 1169-1184, out./dez. 2014 Disponível em: <http://www.ufrgs.br/edu_realidade> 
sabemos, é uma brecha explorada pelo campo da psicanálise, da qual eu não poderia tratar no momento, mas que fica para pensarmos, se quisermos reconhecer elo entre a filosofia da finitude de Montaigne e a problemática do sujeito contemporâneo. Se o fizéssemos, me parece que precisaríamos atravessar o campo dos estudos de um Heidegger, por exemplo, tratando justamente da questão da finitude do ser como modo de marcar um novo paradigma que não é mais da forma idealista de pensar o ser (falo da metafísica do ser como vinha sendo pensada até a soleira do século XX, explicitada, por exemplo, por Habermas, em seu Pensamento pós-metafísico). O humano, a partir daí, tem aparição somente desde uma temporalidade; uma historicidade marcada pelo não absoluto, pela finitude (Heidegger, 1995). Quando a filosofia da educação se inscreve na vastidão de um horizonte filosófico desta natureza, provavelmente se deixará marcar por suas assombrosas provocações. Não mudará o mundo, por certo, nem lhe persegue tal ideia. Mas, quem sabe, poderá inspirar o aluno a "[...] construir uma obra toda sua: ou seja, seu julgamento" (Montaigne, 2002, p. 227).

\section{Conclusão}

A partir da interpretação feita aqui, percebemos pelo menos três eixos da filosofia de Montaigne que se atualizam na filosofia contemporânea igualmente enraizada na relação do ser com a história.

O primeiro deles é a característica antropológica como sendo o chão de sua filosofia que, como vimos, foi fortemente amparada na ressignificação da ideia de homem e mundo produzida no Zeitgeist renascentista (pois seria possível hoje uma filosofia que não se reconhecesse numa ancoragem antropológica). O segundo, o estilo ensaístico como forma que desvela o conteúdo filosófico, pois é possível hoje pensarmos filosoficamente o homem e suas questões a partir de um grande sistema? E, terceiro, a relação da morte e finitude com a filosofia, que é questão fundante da filosofia contemporânea, pois é possível hoje pensarmos no infinito das coisas, do mundo, do homem e da vida? Seria possível trazer a filosofia ao debate sem que levássemos em conta a presença do limite enquanto elemento primordial da vida?

Como sabemos, a filosofia contemporânea está profundamente marcada pela morte, porque os tempos atuais nos mostram constantemente o quanto ela está aí. O corpo e os ideais são frágeis. No entanto, esta ideia esteve sempre na tradição do pensamento ocidental e humano sempre precisou se haver com a face finita da vida, do mundo, de si e isso sempre lhe causou angústia. Parece, então, que esta questão da finitude atravessa a filosofia de Michel de Montaigne como marca fundacional de um pensamento filosófico na medida em que aponta, constantemente, para a impossibilidade de um desvelamento inteiro, completo e total do humano.

Educação \& Realidade, Porto Alegre, v. 39, n. 4, p. 1169-1184, out./dez. 2014.1181 Disponível em: <http://www.ufrgs.br/edu_realidade> 
Assim, podemos dizer que se encontra neste pensamento uma vontade de abandono do sistemático como modo de ficar mais perto possível do humano mesmo. Com isso ele fortalece a filosofia da educação como um exercício ensaístico de um livre pensar que joga esteticamente com o mistério da vida, janela aberta e amplidão entre homem e mundo. Pode ser tarefa da filosofia da educação apresentar a ideia da finitude e da frequentação no mundo como modo de pensar a formação humana, desde sempre ancorada efetivamente em uma filosofia da vida.

Recebido em 24 de julho de 2013 Aprovado em 02 de novembro de 2013

\section{Notas}

1 Expressão tomada de Montaigne (2002, p. 233) a ser desenvolvida neste ensaio.

2 Refiro-me ao desenho conhecido como Homem Vitruviano, de 1490.

3 Arte e ciência.

4 Lembrando que, conforme nos apresenta Pierre Villey, em A Vida e Obra de Montaigne, da edição brasileira de 2002, Livro I, dos Ensaios, nosso filósofo adota para si a máxima, de Pirro, "Que sei eu?", significando sua posição diante das certezas absolutas da razão. Ver, especialmente, o estudo de Luiz Eva sobre o conceito grego antigo de epokhé, “[...] ou suspensão do juízo”, na filosofia de Montaigne que “[...] busca se contrapor às ficções dogmáticas que assumem a razão como instrumento de conhecimento do real" (Eva, 2007, p. 207).

5 Cf. Agnolin, 2002, p. XXI e ss.

6 Segundo a tradução espanhola da Física, de Aristóteles, feita por Guillermo R. de Echandía, o vocábulo spatium corresponde ao que os gregos antigos denominavam tópos, significando um conteúdo relacional ao termo (Echandía destaca este caráter do vocábulo em nota, na página 221, da obra em questão). Nesse sentido, mantemos a ideia de spatium enquanto lugar relacional, algo perceptível na antropologia de Montaigne.

7 Cabe lembrar que, ao contrário do que pode parecer sob tal circunstância, ele mesmo não se considera tomado de melancolia, mas sim passível de um estado de espírito no qual pode se deixar estar pensativo: "Quanto a mim sou não melancólico, mas pensativo” (Montaigne, 2002, p. 129).

8 Dilthey, 2010; Nietzsche, 1998.

9 Bacon, 1973.

10 Descartes, 1987.

11 Sentido orgânico e espiritual da vida conferido desde os gregos (Jaeger, 1986).

12 Nesse sentido, Carpe Diem, ou Aproveita o dia, é uma expressão que pode traduzir a intenção da perspectiva montaigneana enquanto um elogio e uma disposição à vida na sua intensidade, mas também finitude. Nosso filósofo retoma da tradição as palavras de Horácio: "Imagina que cada dia que brilha é para ti o dia supremo; receberás com reconhecimento a hora com que não havias contado" (Horácio apud Montaigne, 2002, p. 128, nota 29). À luz desta

1182 Educação \& Realidade, Porto Alegre, v. 39, n. 4, p. 1169-1184, out./dez. 2014. Disponível em: <http://www.ufrgs.br/edu_realidade> 
filosofia ensaística, pode-se compreender que a vida nos chama atenção para aproveitarmos o dia, saboreando o que ele nos dá como um modo de provocar o acontecimento de nossa autoformação.

13 A Pele que Habito, filme de Pedro Almodóvar, 2011.

\section{Referências}

ADORNO, Theodor. O Ensaio como Forma. In: COHN, Gabriel (Org.). Theodor W. Adorno - Sociologia. São Paulo: Ática, 1994. P. 167-187.

ADORNO, Theodor. Educação após Auschwitz. In: ADORNO, Theodor (Org.). Educação e Emancipação. Rio de Janeiro: Paz e Terra, 1995. P. 119-138.

AGNOLIN, Adone. A Razão Tênue de Montaigne. In: MONTAIGNE, Michel. Ensaios. Livro I. Tradução de Rosemary Costhek Abílio. 2. ed. São Paulo: Martins Fontes, 2002. P. XXI-XXXIII.

ARISTÓTELES. Física. Tradução de Gillermo R. de Echandía. Madrid: Editorial Gredos, 1995.

BACON, Francis. Novum Organum. In: BACON, Francis. Francis Bacon. Novum Organum ou Verdadeiras Indicações Acerca da Interpretação da Natureza. Nova Atlântida. Tradução de José Aluysio Reis de Andrade. São Paulo: Abril Cultural, 1973. P. 17-237.

BLOCH, Marc. A Sociedade Feudal. Tradução de Emanuel Lourenço Godinho. Lisboa: Edições 70, 1982.

CHAUÍ, Marilena. Montaigne. Vida e Obra (Cons.). In: MONTAIGNE, Michel. Montaigne. Vida e Obra. São Paulo: Nova Cultural, 1987. P. VII-XXI.

DESCARTES, René. Discurso do Método. As Paixões da Alma. René Descartes. Tradução de J. Guinsburg e Bento Prado Júnior. São Paulo: Nova Cultural, 1987.

DILTHEY, Wilhelm. Filosofia e Educação. Tradução de Alfred Josef Keller e Maria Nazaré de Camargo Pacheco Amaral. São Paulo: Edusp, 2010.

EVA, Luiz. A Figura do Filósofo. Ceticismo e Subjetividade em Montaigne. São Paulo: Loyola, 2007.

FLICKINGER, Hans-Georg. Para que Filosofia da Educação? 11 Teses. Perspectiva, Florianópolis, v. 16, n. 29, p. 15-22, jan./jun. 1998.

HABERMAS, Jurgen. O Pensamento Pós-metafísico: estudos filosóficos. Tradução de Flávio Beno Siebeneichler. Rio de Janeiro: Tempo Brasileiro, 1990.

HEIDEGGER, Martin. Ser e Tempo (I). Tradução de Márcia de Sá Cavalcante. Petrópolis: Vozes, 1995.

HUIZINGA, Johan. O Outono da Idade Média. Tradução de Francis Petra Janssen. São Paulo: Cosac Naify, 2010.

JAEGER, Werner. Paidéia: a formação do homem grego. Tradução de Artur M. Parreira. São Paulo: Martins Fontes, 1986.

LE GOFF, Jacques. Os Intelectuais na Idade Média. Tradução de Marcos de Castro. Rio de Janeiro: José Olympio, 2003.

MILLER, James. Montaigne. In: Vidas Investigadas. De Sócrates a Nietzsche. Tradução de Hugo Langone. Rio de Janeiro: Rocco, 2012. P. 167-194.

MONTAIGNE, Michel. Ensaios. Livro I. Tradução de Rosemary Costhek Abílio. 2. ed. São Paulo: Martins Fontes, 2002.

Educação \& Realidade, Porto Alegre, v. 39, n. 4, p. 1169-1184, out./dez. 2014.1183 Disponível em: <http://www.ufrgs.br/edu_realidade> 
Finitude, "Frequentação do Mundo" e Formação Humana em Michel de Montaigne

MONTAIGNE, Michel. Ensaios. Livro III. Tradução de Rosemary Costhek Abílio. São Paulo: Martins Fontes, 2001.

NIETZSCHE, Friedrich. Sobre Verdade e Mentira no Sentido Extra-moral. In: NIETZSCHE, Friedrich. Friedrich Nietzsche. Obras Incompletas. Tradução de Rubens Rodrigues Torres Filho. 3. ed. São Paulo: Abril Cultural, 1983. P. 43-52.

NIETZSCHE, Friedrich. Sobre la Utilidade y el Perjuicio d ela Historia para la Vida (II Intempestiva). Tradução de Germán Cano. Madrid: Biblioteca Nueva, 1998.

ROUCHE, Michel. Alta Idade Média Ocidental. Tradução de Hildegard Feist. In: VEYNE, Paul (Org.). História da Vida Privada. Do Império Romano ao ano mil. São Paulo: Companhia das Letras, 1989. P. 399-529.

Rosana Silva de Moura é professora no Programa de Pós-graduação em Educação da Universidade Federal de Santa Catarina, em Filosofia da Educação. Doutora e Mestre em Educação (UFRGS). Graduação em História pela UFRGS. Integra o Grupo de estudos e pesquisas em filosofia da educação e arte/Grafia (UFSC).

E-mail: rosanasilvademoura@gmail.com 